\title{
A Measurement-Theoretic View on the Early Evolution of the Ordering of Chemical Elements
}

\author{
Ave Mets \\ University of Tartu \\ Ülikooli 18, \\ Tartu 50090, Estonia \\ E-mail: avemets@ut.ee
}

\begin{abstract}
Mets (2019) analyses the periodic system of chemical elements notably from the perspective of, inter alia, Patrick Suppes' and Joseph Zinnes' measurement theory (1962), taking for granted its applicability particularly to atomic weight and atomic number-the "primary" ordering principles. Here the applicability of the said theory to these aspects of the periodic table is critically scrutinised from its pre-evolution, or quantification of chemistry and inter-element relations at the end of the 18th century, to some stages of the evolution-briefly the contemporary one, and certain nineteenthcentury versions of the table. It is shown that measurement-theoretic terms, particularly scale types, are not applicable in this subject matter without complications. In addition, there emerges a development towards more substantial exactitude.
\end{abstract}

Keywords: history of chemistry, measurement theory, the periodic table of chemical elements 


\section{Introduction}

Mets (2019) analysed the periodic table of chemical elements from the perspective of theories of measurement by Patrick Suppes and Joseph Zinnes (1962) and David Hand (1995). That article focussed on Hand's distinction between the representational and pragmatic aspects of measurement and its criticism mainly on the basis of the historical evolution and form of the periodic table. However, a full detailed analysis of the periodic table in terms of the representational theory of measurement, advocated by Suppes and Zinnes, was not carried out. Rather, its applicability to the table, or to the atomic weight and atomic number, was taken for granted. This is a serious gap that the article aims to start filling.

Briefly, "[m] easurement is a procedure of assigning numbers to objects or phenomena in the world on the basis of their ordering according to some attribute of theirs" (Mets, 2019, p. 74). For quantitative measurement, a unit is chosen, and other objects or phenomena "can be compared to [it] as to how many unit quantities [...] fit into the particular quantity [...] they represent" (Mets, 2019, p. 76). The assigned scale also ought to preserve this concatenation operation. Mets (2019), however, gives no substantial details of the conceptualisations of chemical elements and of their ordering in measurement-theoretic terms; moreover-no details relevant to determine the scale types, or whether those described by Suppes and Zinnes apply, are considered. When going critically into more detail, applicability may prove questionable.

This article analyses mainly some historical stages of the periodic system in light of the terms of the measurement theory by Suppes and Zinnes. In the first part, I will give further details about the said theory, which will be important for the following analysis. The concept of Suppes and Zinnes is a broader concept of measurement, as they include in it also non-quantitative comparisons and corresponding scales. Scrutinising the evolution of the systematisation of chemical elements, all of those scales need to be considered. Secondly, I will point out some necessary prerequisites, relevant for measurement, in the empirical and theoretical evolution of chemistry that laid the basis for the possibility of the periodic system. Thereby I will outline some stages in the pre-evolution of the periodic system, apply the measurement-theoretic framework to some of the stages, and then to certain periodic tables: for a brief comparison, the contemporary one and, more thoroughly, Newlands' and Mendeleev's tables, having to leave out the results of many other scientists due to space restrictions. Some issues from Mets (2019), such as the metaphysical and technological 
foundations of systematisation, pop up as relevant in those considerations. I will overwhelmingly focus on the "primary" ordering principle_-atomic weight, or number accordingly — but due to space constraints, I must leave the "secondary" one-valency - to be considered on another occasion and here touch upon it only as far as necessary. ${ }^{1,2}$

The disquisition contributes to the understanding of the evolution of chemistry, and the difficulties thereof, in becoming partly an exact science (Vihalemm, 2016); to the understanding of measurement as the basis of exact sciences, and the latter's relation to the world they study.

\section{Measurement theory}

Let us quickly review the key terms of Suppes' and Zinnes' measurement theory (1962). The empirical relational system (ERS) is the real world entities (objects or attributes) that are compared to each other as to their magnitudes, i.e., measured. If two entities fare equally in respect to the property under comparison, they belong to the same equivalence class. One equivalence class may be chosen as the unit and is usually assigned the number ' 1 '. The numerical relational system (NRS) is the numbers and arithmetic assigned to that ERS and is expected to represent the relations and operations possible in that ERS. For instance, if two objects can be concatenated with respect to the measured property, e.g., masspositioned on the scales together-then the addition of numbers assigned to each of them represents the number that can be legitimately assigned to the compound object.

Scales are understood as the set consisting of the ERS, NRS and the mapping from ERS to NRS. Suppes and Zinnes (1962, pp. 12-24) describe five main scales. The absolute scale applies to counting objects and has a natural zero-point - no object is counted — and a natural unit—one object is one unit. For instance, individuals

$1 \quad$ This primacy is expressed in Mets (2019) as Mendeleev's (1869; 1871) and Newlands' (1865; Williamson, 1866) first step of systematising the elements. Although this attribution of primacy only holds topologically, not (chrono)logically, I conventionally stick to this parlance here.

2 While valency is just one aspect of the set of similarities between elements that justified their arranging into groups of similar elements - that I consider the true primary basis of the system-it is the one Mendeleev indicates in his tables as the secondary basis of ordering (see the section 'Mendeleev's table'). In any case, I cannot provide any detailed analysis of it here due to space restrictions, and only imply it as an inescapable ordering principle for the periodic table. 
present in a room at a certain time. The scale consists of positive integers and allows addition and positive subtraction; it is unique up to identity transformation. The ratio scale applies to continuous measurements such as mass and length, having potentially real numbers (practically decimal fractions) as assigned numbers, a natural zero point and an arbitrary, non-natural unit such as metre or kilogram. It is unique up to a linear transformation. The interval scale has neither natural zero point nor natural unit but is defined via two fixed points and a scale divided between those into a number of units. Such is temperature, where one fixed point (on the Celsius scale) represents the point of freezing of water, assigned 0 , and the second fixed point represents the point of boiling of water, assigned 100, and the space between them is expectedly divided into 100 units. The interval scale, like the ratio scale, is unique up to linear transformation. The ordinal scale only represents the ordering of an attribute, but no unit, and the only relation retained by the numbers is a qualitative comparison as to the intensity of the property. Such is the Mohs' scale of mineral hardness, where exact numbers representing points on the scale are assigned to chosen minerals, which therefore serve as reference points, and other minerals' positions on the scale are determined by scratching: the mineral which has the ability to scratch another mineral is assigned a higher number. Ordinal scales are unique up to a monotone transformation, preserving the order of measurands. The nominal scale is arbitrary, mere classification of objects with numbers (or even mere numerals), with no arithmetic operations applying and uniqueness is one-to-one.

In the discussion, two fundamental problems of the measurement theory prove to be relevant - that of representation and that of uniqueness.

1) The representation problem: Does the chosen NRS truthfully represent the intended ERS, representing its operations and relations? For instance, the Celsius scale of temperature in itself suggests no lower limit to temperatures, implying that $-1,000^{\circ} \mathrm{C}$ might be a legitimate occurring temperature, even though our current empirical knowledge tells otherwise-that there is a lower limit, or absolute zero point, of temperature.

2) The uniqueness problem: What is the scale type resulting from a measurement procedure? The Celsius scale and the Fahrenheit scale represent temperature equally well and are translatable into each other, neither also having a built-in lower limit and both defined as phenomena observable in everyday conditions with the naked eye. The Kelvin scale, in contrast, has an absolute zero point where theoretically the true lowest temperature lies, and is defined after, or refers to, the underlying microphenomenon. 
In the following analysis, I seek to answer the following questions inspired by measurement-theoretical approach: What are the numbers, or NRS, assigned to the studied phenomenon, the ERS, underlying the systematisation of chemical elements? To which objects or phenomena (the ERS) are the numbers assigned, and by that what is implied about it? What is the unit object, if there is any? Which scale is implied by the assignment?

\section{Pre-evolution of the periodic system}

First of all, a decisive step in the pre-evolution of the periodic system is certainly chemistry's becoming quantitative-in the second half of the 18th century, weight and its measurement came to be considered fundamental in chemical methodology. Thus the weights of reactants and the results of reactions were measured and compared against each other, giving birth to the notion 'equivalent weight', which stands for the comparative weight with respect to a standard substance (reactant), such as hydrogen or oxygen, and further on to 'atomic weight' which remained the primary basis of periodic systems until it was replaced by atomic number.

Comparisons of the weights of combined substances led to another crucial layer in the foundation of systematising them-the fixed proportions in which they combine. Even though the first attempt at determining atomic or relative weights by Dalton used non-reacting mixtures of substances and mechanistic speculation to explain the fixed proportions (Venable, 1896, p. 15; Dalton, 1805 , pp. $287,272 \& 285)$, the same was observed in reactions as well. This indicated certain numerical, or numerically representable relations between the substances that ultimately led to numerical determination and identification of chemical substances, especially elements. ${ }^{3}$

\footnotetext{
3 An alternative hypothesis existed, put forward most notably by Claude Louis Berthollet (1748 -1822 ) on the basis of his experiments, that substances combine in continuously varying proportions, allowing no fixing of compositions of substances (Vihalemm, 2019/1981, pp. 117-120). This hypothesis, however, found no broader support among chemists of the time.
} 


\section{Prout's hypothesis}

Another item relevant in terms of measurement in the science of chemistry was Prout's hypothesis (1815 and 1816, by William Prout, 1785-1850) with its two readings (Gordin, 2004, p. 215) that I would call metrological and ontological. Prout's metrological hypothesis states that the atomic weights of all elements are integral multiples of that of hydrogen. Prout's ontological hypothesis states that all elements consist of a primal matter, or protyle, whereas the said primal matter was thought to be hydrogen. The metrological hypothesis pertains to the NRS, or which numbers and arithmetic are assigned to a phenomenon, and here it is namely assumed that the numbers to be pursued should be whole multiples of hydrogen's atomic weight. The measurement procedure of comparison in reactions with hydrogen, the latter having been accepted as a standard substance and assigned number 1 as the weight unit, gave rise to the ratio scale of atomic weights. If Prout's metrological hypothesis were to hold, the other elements, therefore, were expected to have integral atomic weights as well. The ontological hypothesis concerns the ERS as the objects or phenomena that the numbers are assigned to-namely, compounds of the same fundamental particle.

The chemists who believed in Prout's hypothesis tried to prove it while determining the atomic weights of substances. So did Jean-Baptiste Dumas (1800-1884), who conducted experiments to determine the atomic weights of many substances for that aim (e.g., Dumas, 1859). Many a substance reluctantly yielded an integral atomic weight, but most notably so chlorine which defied all such attempts, rigidly holding the atomic weight 35.5. Many other substances fared no better. See the example from Dumas (1859, pp. 10-12), where he carries out reactions with different amounts of reactants to determine the atomic weight of barium against standard reactants (Fig. 1). The results of the experiment clearly indicate the statistical nature of the concept of atomic weight (i.e., atomic weight was to be averaged over a set of measurements).

Thus Dumas suggested that a protyle may be $1 / 4$ of hydrogen instead (Dumas, 1859, p. 81; Venable, 1896, pp. 59-60). Jean Charles Galissard de Marignac (1817-1894) had proposed the protyle to be $1 / 2$ of hydrogen (Venable, 1896, p. 59). Other suggestions for the fraction were made (Venable, 1896, pp. 63-65; Scerri, 2007). Let us consider the possible system of chemical elements just in case there is a protyle $1 / 2$ of hydrogen, the groupings of which make up all elements (Fig. 2). Hydrogen is composed of 2 protyle particles, lithium of 14, glucinium (= beryllium) of 18 , etc. (Here, the 1860's elements are taken as example, as 
Chlorure prodult avec te sulfate naturel d'Auvergne. .

I. 1,7585 de chlorure de barium exigent 1,826 d'argent.

II. 3,842

III. 2,1585

IV. 4,0162

3,988
3,2405
4,168

(ii)

Elles donnent pour l'équivalent du barium :

$$
\begin{aligned}
& \text { I, } \ldots \ldots 68,50 \\
& \text { II. ... . 68,54 } \\
& \text { III.. .. } 68,54 \\
& \text { IV. . . . } 68,56
\end{aligned}
$$

$\begin{array}{lllll} & & & \text { Equiv. } \\ \text { v. } & 1,6625 \text { de chlor. de bar. exigent } 1,727 & \text { d'argent } 68,47 \\ \text { vi. } 2,4987 & & 2,5946 & 68,50 \\ \text { VII. } 3,4468 & : & 3,579 & 68,51 \\ \text { VIII. } 4,0822 & : & 4,2395 & 68,49 \\ \text { IX. } & 4,2063 & & 4,3683 & 68,49 \\ \text { X. } & 4,4564 & & 4,629 & 68,49 \\ \text { XI. } 8,6975 & * & 9,031 & 68,51\end{array}$

XII. 2,2957 de chlor. de bar. exigent 2,3835 d'arg. 68,52
XII. 4,1372
XIV. 4,2662

Figure 1. Measurement results for equivalent weights from Dumas (1859, pp. 10-12). "Chloride produced with natural sulphate of Auvergne. 1,7585 of barium chloride requires 1,826 of silver; [etc. for I, ..., IV]." "They give as equivalents of barium:

\begin{tabular}{|c|c|c|c|c|c|c|c|c|c|c|c|c|c|c|}
\hline $1 / 2$ & $\begin{array}{l}1 \\
H\end{array}$ & $11 / 2$ & 2 & $2 \frac{1}{2}$ & 3 & $31 / 2$ & 4 & $41 / 2$ & 5 & $51 / 2$ & 6 & $61 / 2$ & $\begin{array}{l}7 \\
\mathrm{Li}\end{array}$ & $71 / 2$ \\
\hline 8 & $81 / 2$ & $\begin{array}{l}9 \\
\mathrm{GI}\end{array}$ & $\begin{array}{l}9^{1 / 2} \\
\mathrm{Be}\end{array}$ & 10 & $10 \frac{1}{2}$ & $\begin{array}{l}11 \\
\text { B }\end{array}$ & $11 \frac{1}{2}$ & $\begin{array}{l}12 \\
C\end{array}$ & $12^{1 / 2}$ & 13 & $13 \frac{1}{2}$ & $\begin{array}{l}14 \\
\mathrm{~N}\end{array}$ & $14 \frac{1}{2}$ & 15 \\
\hline $15 \frac{1}{2}$ & $\begin{array}{l}16 \\
0\end{array}$ & $161 / 2$ & 17 & $171 / 2$ & 18 & $18 \frac{1}{2}$ & $\begin{array}{l}19 \\
\mathrm{~F}\end{array}$ & $19 \frac{1}{2}$ & 20 & $201 / 2$ & 21 & $21 \frac{1}{2}$ & 22 & $22 \frac{1}{2}$ \\
\hline $\begin{array}{l}23 \\
\mathrm{Na}\end{array}$ & $23 \frac{1}{2}$ & $\begin{array}{l}24 \\
\mathrm{Mg}\end{array}$ & $241 / 2$ & 25 & $251 / 2$ & 26 & $261 / 2$ & 27 & $\begin{array}{l}271 / 2 \\
\mathrm{Al}\end{array}$ & $\begin{array}{l}28 \\
\mathrm{Si}\end{array}$ & $281 / 2$ & 29 & $29 \frac{1}{2}$ & 30 \\
\hline $301 / 2$ & $\begin{array}{l}31 \\
\mathbf{P}\end{array}$ & $31 \frac{1}{2}$ & $\begin{array}{l}32 \\
5\end{array}$ & $32 \frac{1}{2}$ & 33 & $33 \frac{1}{2}$ & 34 & $341 / 2$ & 35 & $\begin{array}{l}35^{1 / 2} \\
\mathrm{Cl}\end{array}$ & 36 & $361 / 2$ & 37 & $371 / 2$ \\
\hline 38 & $381 / 2$ & $\begin{array}{l}39 \\
\text { K }\end{array}$ & $391 / 2$ & $\begin{array}{l}40 \\
\mathrm{Ca}\end{array}$ & $401 / 2$ & 41 & $41 \frac{1}{2}$ & 42 & $42 \frac{1}{2}$ & 43 & $431 / 2$ & 44 & $44 \frac{1}{2}$ & $\begin{array}{l}45 \\
?\end{array}$ \\
\hline $45 \frac{1}{2}$ & 46 & $461 / 2$ & 47 & $471 / 2$ & 48 & $48 \frac{1}{2}$ & 49 & $491 / 2$ & $\begin{array}{l}50 \\
\mathrm{Ti}\end{array}$ & $501 / 2$ & $\begin{array}{l}51 \\
\mathrm{~V}\end{array}$ & $\begin{array}{l}511 / 2 \\
V\end{array}$ & $\begin{array}{l}52 \\
\mathrm{Cr}\end{array}$ & $521 / 2$ \\
\hline
\end{tabular}
$[I, \ldots$, IV]." Reactions $V$ to XI have been carried out with chloride by Mister Kuhlmann, XII to XVI with that "obtained with the help of pure artificial carbonate" (Dumas, 1859, pp. 10-12).

Figure 2. Hypothetical elements if a protyle equals $1 / 2 \mathrm{H}$. Black indicates the anonymous table from 1869 (Venable, 1896, p. 68), red-Mendeleev, 1869.

Note 1: For the lack of space I confine myself to the first 105 elements suggested by those presumptions; further elements can be analogously deduced, and identified, or not, with existing ones.

Note 2: This table does not, despite its tabular form, represent any periodicity; the order is considered to hold between cells only according to rows, not columns.) 
noble gases were not yet known). But consider how many substances would have been unknown on this basis: one protyle, 3 to 13 protyles, 15 to 17 protyles, etc. - that is, elements with atomic weights of $1,2 \frac{1}{2}, \ldots, 61 \frac{1}{2}$, etc. Why would this primal particle not form such groupings? the table above (Fig. 2) shows the elements that should exist, composed of up to 105 protyle particles, indicating their atomic weights, and elements known by that time in the table (and one hypothesised by Mendeleev in 1869-the '?' with the atomic weight of 45).

Usually, though, $\mathrm{H}=1$ remained the weight unit for comparing other elements' weights against it directly or indirectly. Other systems existed. Jöns Jacob Berzelius (1779-1848), who made precise measurements, took oxygen $\mathrm{O}=100$ as the unit of weight; Berzelius $(1833$, pp. 180,187) indicates the atomic weights of $\mathrm{O}$ and $\mathrm{H}$, respectively. However, those systems were convertible into each other, and the corresponding tables were given by him (Berzelius, 1835, pp. 250, 323; Dunsch, 1986, p. 58). In either case, the ratio scale is applied with no a priori determination of whether it is of natural, (positive) fractional or real numbers. The latter restriction was related to an individual chemist's conviction about the primal matter or its absence, and that could motivate them to round off the measured atomic weights to attain the desired NRS.

\section{Döbereiner's triads}

Johann Wolfgang Döbereiner (1780-1849) was the first to notice arithmetic relations between the atomic weights of chemically similar substances. He took into account both the simple bodies as well as their compounds, for instance, alkali metals $(\mathrm{L}(\mathrm{Li}), \mathrm{K}, \mathrm{Na})$ and their compounds with oxygen $(\dot{\mathrm{L}}, \dot{\mathrm{K}}, \dot{\mathrm{Na}})$, but also specific weight. With the latter, he even presumed that elements are similar because their specific weights form an arithmetic sequence (Döbreiner, 1829, p. 302). He found arithmetically simple relations between all those sets of substances according to equivalent weights. Below is an excerpt from his 1829 article (Fig. 3).

Clearly, Döbereiner was not able to devise any table or conceive of periodicity due to the scarcity of knowledge about elements and their properties at his time. Still, he does hypothesise that the triadic relations ("Trias") could be a law (Döbereiner, 1829, p. 303). The atomic weights he uses are obtained from other chemists and different measurement systems. In the same paper, he uses both the system where the unit is $H$, assigned ' 1 ', and Berzelius' system. 


$$
\begin{aligned}
& \text { Intensität } \\
& \text { a) Salzbilder und deren Säuren. der chem. } \\
& \text { Anziehung } \\
& 221,325=\mathrm{Cl} .455,129=\mathrm{H \epsilon l} .942,650=\dddot{\mathrm{El}} \quad 3 \\
& 789,145=\text { J } .1590,770=\text { Н } .2078,290=\text { J } \quad \text { I } \\
& \overline{\frac{1010,470}{2}}=\mathrm{Br} \cdot \frac{2045,899}{2}=\mathrm{HBr} \cdot \frac{3020,940}{2}=\ddot{\mathrm{Br}} \quad 2
\end{aligned}
$$

Figure 3. An example of the calculation of relations between chemically similar elements and their compounds ("salt builders and their acids") as to their atomic weights, also indicating the order of the intensity of their affinities on the right (Döbereiner, 1829, p. 303). Atomic weights are from Berzelius' system, with $O$ as the unit assigned '100' and other substances compared to it as its (nonintegral) multiples. ' $\mathrm{J}$ ' = 'l'; a dot above an element sign marks an oxygen atom; a strikethrough—a double atom (Berzelius, 1835, pp. 90-91).

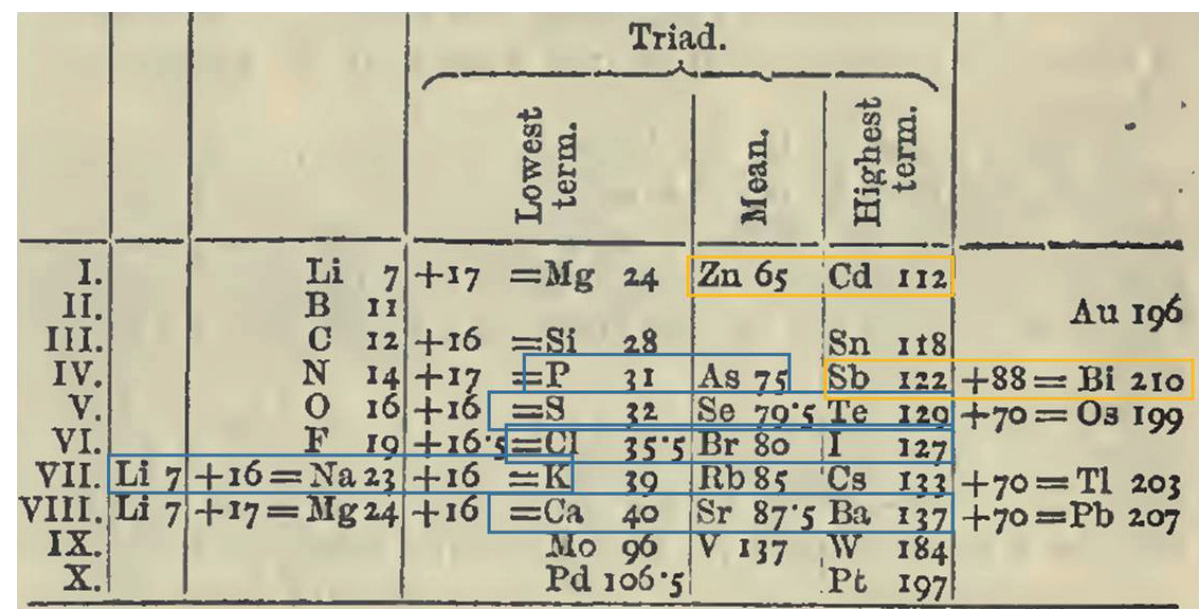

Figure 4. Extended triads in Newlands (1864, p. 59). The blue boxes indicate the triads that Döbereiner had mentioned ("The group of [P] and [As] misses the third factor"); the yellow boxes indicate what he suspected to be parts of triads (Döbereiner, 1829).

Berzelius was no proponent of either Prout's hypotheses or of the hypothesis of triads, which he deemed to be mere numerology. He believed that as the atomic weights come to be determined ever more precisely, the triadic relations evade (Venable, 1896, pp. 22-23, 31). He did nonetheless note isomorphisms between elements (e.g., Berzelius, 1835). Isomorphisms or analogies underlay the triads' growing into $\mathrm{n}$-ads, which means that groups formed by recognisably allied elements included more than three members (Fig. 4). 
For instance, the triad $\mathrm{Li}, \mathrm{Na}, \mathrm{K}$ was complemented with $\mathrm{Rb}$, Cs and $\mathrm{Tl}$, and John Alexander Reina Newlands (1837-1839) suspected one more element between $\mathrm{Cs}$ and $\mathrm{Tl}$ on numerical basis (Newlands, 1863, p. 71); hence it had become a sextad and promised to become a septad. At the same place, Newlands brings forth numerical relations between the atomic (equivalent ${ }^{4}$ ) weights of the members of groups, using the equivalents of the lightest of the members as units (Fig. 5).

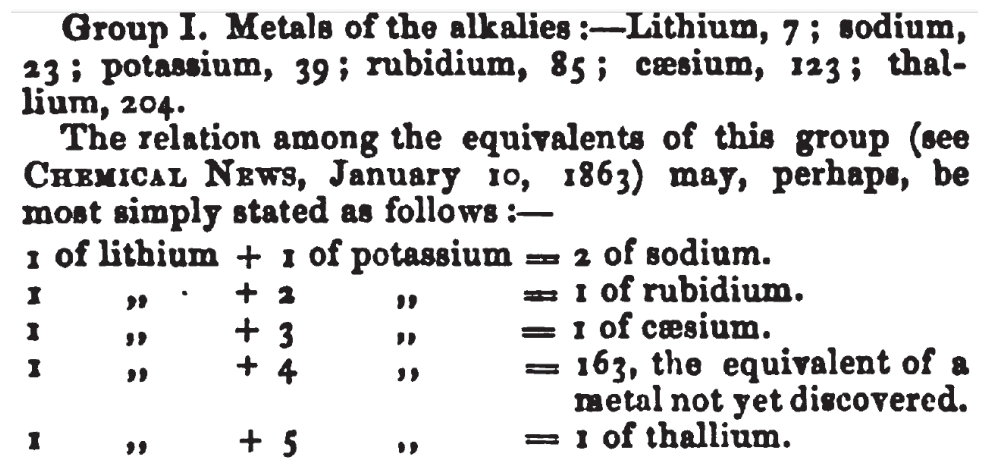

Figure 5. Arithmetics of Newlands' groups (Newlands, 1863, p. 71): the lighter elements, or the lower members of the first triad, serve as units to calculate the higher members of the triads in the same row. Similar calculations are shown for other groups, although mostly to a lesser extent.

Newlands (1863) discerns between 11 groups of allied elements, each containing $3 . . .9$ members. He brings forth what I interpret as intra-triad or intra-group arithmetics, of which there are about three kinds. In one version, triads have their own unit in the sense that the equivalents of (some) other elements in that group are a sum of those, as Figure 5 illustrates: $\mathrm{Li}$ (equivalent 7) and $\mathrm{K}$ (39) for Group I, $\mathrm{Be}$ (6.9), $\mathrm{Al}$ (13.7) and $\mathrm{Zr}$ (33.6) for Group III, P (31) and Sb (120.3) for Group VII, etc. In other cases, the traditional average of equivalents is the arithmetic basis of the groups-the difference between the equivalents of members of groups are other than the equivalent of one of its members; and the differences may be bigger (e.g., around 23 or 46) or smaller (around 1...4). Then there are hybrid arithmetics combining the sums/differences and coefficients. (Mathematically speaking, the triadic arithmetics is $\mathrm{E}_{\mathrm{k}}=\mathrm{a} \times\left(\mathrm{b} \times \mathrm{E}_{1}+\mathrm{c} \times \mathrm{E}_{\mathrm{m}}\right), \mathrm{E}_{\mathrm{n}}$ being the equivalent of element $\mathrm{n}$,

4 Many chemists, including Newlands, avoided using the term 'atom' or 'atomic' for its metaphysical connotations, and used 'equivalent' or 'equivalent weight' instead of, or much more often than 'atomic weight'. 
a, b, c being integers; however, Newlands makes no such generalisation, proceeding piecemeal instead.) $\mathrm{Mg}$ and Li belong to more than one group at once, hence potentially participating in the definitions of different units. Also, most groups manifest a mix of the said arithmetics. Therefore, the numerical basis defining the triads is fluctuant, enabling no firm implications about the underlying reality of elements nor predictions concerning the scales, even if Newlands himself attempts some (the hypothesised septad mentioned above).

As to the numbers assigned to affinities, Döbereiner (Fig. 3) uses those to indicate one more argument towards the triadic relations - that the middle element is a near arithmetic average of the two extreme ones. In this case, unlike the exact ratios of units assigned to weights, the NRS is less strict, forming an ordinal scale instead. The numbers indicate more or less vigorous chemical activity. Should the triads be extended to $\mathrm{n}$-ads on the heavier end, provided that the incoming elements react less vigorously, negative numbers should be added to this scale. The negativity (or fractionality, should that be relevant) in this scale would have no other meaning but to maintain the order of apparent vigour of reactivity.

\section{Versions of the periodic system in measurement- theoretic terms}

The main attribute considered here is the horizontal ("primary") ordering principle-atomic weight, or atomic number, in the case of the contemporary table. The second indispensable attribute for the systematisation, or part thereof-the valency or chemical properties-will play a role in explaining the basis of systematisation, but I do not attempt to, nor cannot provide, any nearly satisfactory account of it in measurement-theoretic terms here. This is primarily because it would presuppose an arithmetic of the system which has not yet been arrived at, despite claims to otherwise. ${ }^{5}$ I do not assume to be able to accomplish (especially in one short article) what has eluded more knowledgeable scholars.

In this part, I disrupt the chronological sequence of events for theoretical clarity. Namely, the historical periodic tables have sometimes been imputed with contemporary ideas. To clarify the erroneousness of those imputations, the contemporary table will be briefly analysed first.

5 Hettema \& Kuipers, 1988; 2000; for a contrary position, cf. Scerri, 1997; 2005; Restrepo, 2018. 


\section{Contemporary table}

The primary ordering principle in the contemporary periodic table is the atomic number, referring to the number of protons in the nucleus of the atom. The secondary ordering principle is valency, or the capacity of an atom to combine with univalent atoms - but a focussed discussion of this, and chemical similarity more generally, must await another occasion. The NRS of atomic numbers is natural numbers starting with 1 and currently reaching about 118 . The ERS of it, the number of protons, pertains to theoretically countable and indivisible entities. This implies natural unit to assign number ' 1 ' —one proton, corresponding to the $\mathrm{H}$ atom. The scale featuring a natural unit and natural numbers is absolute scale, in which the procedure of measurement is basically counting the individuals, and each individual is as much a unit $(=1)$ as any other. This, however, does not quite correspond to how elements are assigned atomic numbers-on the basis of individual protons. Rather, those numbers are assigned to sets of protonsnumber ' $\mathrm{n}$ ' is assigned to the set of $\mathrm{n}$ protons, and the individual protons in a nucleus have no chemical import as long as no nuclear reactions are going on that would change the element into another. ${ }^{6}$ Therefore, here already the applicability of the scales considered in Suppes and Zinnes (1962) becomes unclear.

The difference also comes forth in operations that can be performed on those two scales - the absolute scale and that of atomic numbers. In the absolute scale, a sum $j=k+l$, where $k, l$ are integers, means that a group of $k$ individuals merged with a group of $\mathrm{l}$ individuals makes up a group of $\mathrm{k}+\mathrm{l}=\mathrm{j}$ individuals. Considering the atomic numbers, "a group of k protons" (element k) chemically "merged" with a "group of 1 protons" (element l) does not make up an analogous "group of $\mathrm{j}$ protons" (element $\mathrm{j}$ ). Thus the numbers do not pertain to protons as individuals but rather to sets of protons defining the elements $\mathrm{k}$ and $\mathrm{l}$, respectively, to their combination-the compound $\mathrm{E}_{\mathrm{k}} \mathrm{E}_{\mathrm{l}}$, but not to $\mathrm{E}_{\mathrm{j}}$. Thereby in most practically relevant contexts that sum of atomic numbers is not essential, as Mets (2019) also mentioned, even though it has a true reference in its ERS. Now, when the atomic number is something that defines or individuates the element, it works like a name for it in chemistry: one can say 'element 78 ' instead of 'platinum' or 'element 118' instead of 'oganesson', etc.; $\mathrm{Pt}=78$ and $\mathrm{Og}=118$ - the number and the name are the same. When numbers function as names, it is a nominal scale

6 Also atomic number as such has no role in a chemistry laboratory, but as it theoretically defines the element, it does have a meaning in chemistry at large and is thus relevant in the current disquisition. 
(Suppes \& Zinnes, 1962). In the nominal scale, the only applicable operation is identity relation, like the mentioned $\mathrm{Og}=118$ and $\mathrm{Pt}=78$. This even implies no order, which clearly does exist in the periodic table and is relevant in chemistry. Also, the numbers assigned in a nominal scale have no substantial relation to the ERS, which, again, does not hold with the periodic table—its NRS is clearly substantially and uniquely referring with respect to its ERS. Moreover, the NRS can, due to this relation, be extended to yet unexplored values-new elements can be hypothesised and potentially created with a nucleus of a higher charge than those discovered in nature, or thus far created in particle colliders.

\section{Newlands' table}

Newlands dedicated much of his career as a chemist to classifying chemical elements and finding a numerical order between them. As mentioned above, he expanded the previously known triads into n-ads, while still using the term 'triads', implying those as the main unity: triadic relations can be used to predict correct equivalents according to the group into which an element is assigned. $\mathrm{He}$ came to formulate the law of octaves (a sort of $\mathrm{n}$-ads): "the elements analogous in their properties exhibit peculiar relationships, similar to those subsisting in music between a note and its octave" (Williamson, 1866, p. 113; see also Newlands, 1865). Based on this idea, he drew versions of corresponding tables of chemical elements, of which two are presented and analysed here-one before and one after the publication of Mendeleev's first versions in 1869 and 1871.

For the 1866 table (Fig. 6 on p. 18), Newlands arranged the elements increasingly according to their atomic weights (equivalents), just what Mets (2019) mentions as the first step, or primary principle, of ordering. After that he assigns, correspondingly, natural numbers to them, making up what could be understood as an ordinal scale. If two elements have very similar equivalents, they are given the same number, and are thus treated as belonging to the same equivalence class. The secondary principle of ordering, turning the string of elements into a table, is chemical analogy: Newlands aligns analogous elements from left to right. (Both steps have contingencies: by linear ordering, Newlands swaps places of some elements, namely Te and I, Y and $\mathrm{Zn}, \mathrm{Ti}$ and $\mathrm{Cr}, \mathrm{Zr}$ and $\mathrm{Ce}+\mathrm{La}, \mathrm{Sn}$ and $\mathrm{U}$, to get analogous elements to repeat in more regular intervals of seven or a multiple of seven, and due to tabular ordering, one row can contain elements of different groups, not only of one group.) 
Table II.-Elemente arranged in Oolaves.

\begin{tabular}{|c|c|c|c|c|c|c|c|c|c|c|c|c|c|}
\hline No. $\mathrm{N}$ & No. & & 7o. & $"$ & No. & ${ }^{5}$ & No. & & No. & & No. & & No. \\
\hline $\begin{array}{lll}\mathrm{H} & \mathrm{F} \\
\mathrm{L} & \mathbf{2} & \mathrm{Na} \\
\mathrm{G} & \mathbf{M g} \\
\mathrm{Bo} & \mathbf{A l} \\
\mathrm{C} & \mathrm{Al} \\
\mathrm{N} & 6 & \mathrm{P} \\
\mathrm{O} & 7 \mathrm{~S}\end{array}$ & \begin{tabular}{c|}
8 \\
9 \\
10 \\
11 \\
12 \\
13 \\
14
\end{tabular} & $\begin{array}{l}\mathrm{Cl} \\
\mathrm{K} \\
\mathrm{Ca} \\
\mathrm{Cr} \\
\mathrm{TH} \\
\mathrm{Mn} \\
\mathrm{Fe}\end{array}$ & \begin{tabular}{l|l|l}
15 & $\mathrm{C}$ \\
26 & $\mathrm{C}$ \\
17 & $\mathrm{Z}$ \\
19 & $\mathrm{Y}$ \\
18 & $\mathrm{LI}$ \\
20 & $\mathrm{~A}$ \\
21 & $\mathrm{~S}$
\end{tabular} & 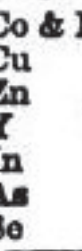 & $\begin{array}{r}\text { N1 } 22 \\
23 \\
24 \\
24 \\
25 \\
26 \\
27 \\
28\end{array}$ & 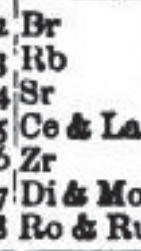 & $\begin{array}{r}29 \\
30 \\
31 \\
033 \\
33 \\
034 \\
034 \\
035\end{array}$ & 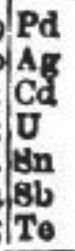 & \begin{tabular}{l|l}
36 & 1 \\
37 & \\
38 & \\
40 & 1 \\
39 & \\
41 & \\
43 &
\end{tabular} & 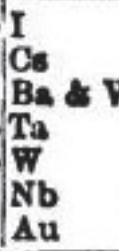 & $\begin{array}{r}44 \\
45 \\
47 \\
48 \\
49\end{array}$ & $\begin{array}{l}\mathbf{H g} \\
\mathrm{T} \\
\mathrm{Pb} \\
\mathrm{Bd} \\
\mathrm{Th}\end{array}$ & $\begin{array}{l}50 \\
51 \\
52 \\
53 \\
54 \\
55\end{array}$ \\
\hline
\end{tabular}

Figure 6. Newlands' 1866 table (Williamson, 1866, p. 113).

Table 6a shows 11 groups of analogous elements (Newlands, 1863) plotted on his 1866 table to visualise how the analogies guide the construction process from the empirical aspect.

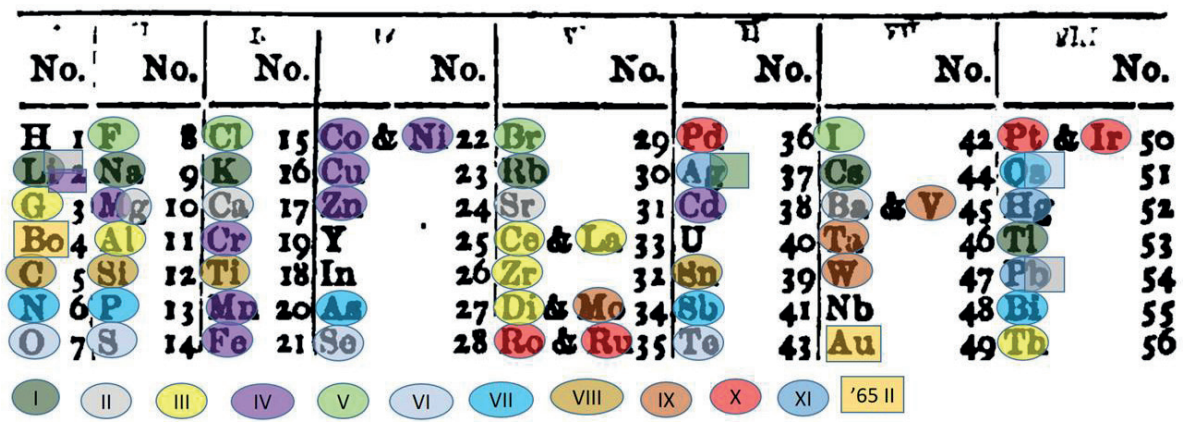

Figure 6a. Newlands' 1866 vs his 1863 groups I, ..., XI of allied elements, indicated with different colours and shapes and in 1865 added classifications on tiny coloured shapes on the right. Magnesium was placed both in Groups II and IV in Newlands (1863), Li into three groups in Newlands (1865); see Figure 4.

As can be seen, most rows contain elements of four different groups intermittently, and one group can be spread among up to six rows. Only Groups II, V, VI and VIII keep to one single row. This raises the question of how systematically a table of this kind can present the elements and their properties known at that time and also of how distinctly and firmly can the boundaries be drawn between them at that time, taking into account, inter alia, Newlands' own placing of $\mathrm{Li}$ and $\mathrm{Mg}$ into several groups at once; in measurement-theoretic terms-how distinct were the equivalence classes to be assigned numbers to, whatever kind of scale could be implied? The numbers I, ..., XI that Newlands assigned to the groups were meant as mere names, or the nominal scale, as he explicitly states (Newlands, 
1865, p. 59); nonetheless there are underlying comparisons in different aspects that justify appointing elements into one group or another. A hint to which aspects those were is given in Newlands (1865, p. 60): he assigns boron and gold into one group due to their atomicity (i.e., valency), and concedes that in their physical properties, elements are often more similar to those of different groups than of their own group, to which they are similar chemically. Hence, valencies or chemical reactivity were the basis of forming groups, which is clearly a quantitative aspect. However, he also seems to confer elements to groups according to their elegant triadic relations to other members of those groups, and those are between atomic weights (e.g., silver in the group of alkali metals). In the following, the ordinal numbers assigned to the equivalent are discussed.

One thing that the ordinal numbers assigned to the elements do is render the arithmetic relations between analogues more exact, as atomic weights were, firstly, statistical averages obtained from empirical situations prone to uncertainty and inexactness characteristic of empirical measurements, as mentioned above (see 'Prout's hypothesis'). Secondly, most equivalents of analogous elements do not stand in exact arithmetic relations with each other in the sense as is expressed with a formula $E_{k}=E_{1}+16 m$, $m$ being an integer, analogously with the ordinal numbers, where 16-the equivalent of oxygen-is the unity of difference in terms of equivalents (Newlands, 1964, p. 59); ${ }^{7}$ instead, they would additionally require a term for deviation tolerance $\varepsilon: \mathrm{E}_{\mathrm{k}}=\mathrm{E}_{1}+16 \mathrm{~m} \pm \varepsilon .^{8}$ This reveals that Newlands did not mean the scale to be ordinal, as the latter only preserves the ordering relation of measurands, but he also aimed to use substantial arithmetic operations with them.

Now, what kind of a scale is it? To determine this, we should also look at what it refers to, what is the ERS, what can be done with it. While the reference quantities - atomic weights - make up a ratio scale where $\mathrm{H}=1$ is defined as the unit of mass, used to determine the masses or equivalents of all other elements, and this is done on the empirical basis of real amounts of substances in reactions, where addition captures the procedure of adding substances or removing them, Newlands' assigned numbers do not capture such relationships. They indicate the order, but not the value, of elements according to their equivalents, and

\footnotetext{
Also Alexandre Émile Béguyer de Chancourtois (1820-1886) considers 16 as the "unit of length" or of periodicity, and $1 / 16$, or the characteristic number of hydrogen, as the unit of distance between consecutive elements, despite their real atomic weights (Béguyer de Chancourtois, 1862). Like Newlands, he hypothesised a uniform periodicity (of 16) for the entire realm of chemical elements but unlike Newlands (1866), he left gaps for yet unknown elements in his helical table.

8 Also Giunta (1999, p. 27) points out the relative exactitudes of these two approaches.
} 
they do so only partially due to occasional transpositions. Rather they indicate the order inside the table. Of other arithmetical relations or operations, neither identity nor addition are defined in this scale, as some numbers refer to more than one element of the ERS, and the summation does not refer to anything in the real world. I claim that the numbers refer to a place in the string of elements, or in the table correspondingly, but to nothing beyond that.

To provide evidence to this claim, let us compare the power of predictability of the contemporary table and Newlands' table that should emanate from the extrapolation of the NRS on the basis of the ERS it refers to. First of all, the prediction already made by Newlands previously on the triadic bases_-an alkali metal with equivalent 163 (see Fig. 5 on p. 14), and an element right after silicon (eka-silicium) with equivalent 73 , should have empty spaces left between $\mathrm{Ta}$ and $\mathrm{W}$, and $\mathrm{Zn}$ and As, respectively. No such places are left for them. Newlands conceded that the form of the table is not fixed and can be extended to consist of 9,10 , or whatever number of rows, should new (kinds of) elements be discovered (Newlands, 1866), implying the possibility to expand the table to include new rows; and the last column indicates the same analogies in rows as the previous ones (Williamson, 1866, p. 113), implying the possibility to expand the table to the right. Let us consider the options.

Suppose a new element is discovered. If its equivalent is higher than the previous ones, it can start a new column; if less than the greatest found thus far, it should find a place somewhere inside. If now it is of an entirely new type, should it start a new row? Does the table give us instructions or indications of what to do with that element? There are no empty places left in the table; hence, if the new element is placed on a new row, that row would have all other places empty contrary to the rest of the table. On the other hand, the table has many different kinds of elements in each of its rows; thus, one can conclude that the new type of element can also go into one of the rows. If its equivalent is sufficiently distinct from all the others, it shifts all the following elements one place further, thereby assigning those new numbers. If it is difficult to distinguish its equivalent from others, it should be placed side by side with an already existing element without violating any principle of the table (see $\mathrm{Ba}$ and $\mathrm{V}, \mathrm{Di}$ and Mo occupying one place in Fig. 6a). The same applies to a new element of an already known type. Furthermore, Newlands expresses no restriction upon the number of elements that could occupy the same place in the table. In Figure. 7, I speculate about how new elements could be placed, leaving a special row to noble gases. 


\begin{tabular}{|l|l|l|l|l|l|l|l|}
\hline $1 \mathrm{H}$ & $9 \mathrm{~F}$ & $17 \mathrm{Cl}$ & $25 \mathrm{Mn}$ & $33 \mathrm{Br}$ & $41 \mathrm{Ru} \& \mathrm{Rh}$ & $49 \mathrm{I}$ & $57 \mathrm{Yb} \& \mathrm{Lu} \& \mathrm{Hf}$ \\
\hline $2 \mathrm{He}$ & $10 \mathrm{Ne}$ & $18 \mathrm{Ar}$ & $26 \mathrm{Fe} \& \mathrm{Co} \& \mathrm{Ni}$ & $34 \mathrm{Kr}$ & $42 \mathrm{Pd}$ & $50 \mathrm{Xe}$ & $58 \mathrm{Ta} \& W \& \mathrm{Re}$ \\
\hline $3 \mathrm{Li}$ & $11 \mathrm{Na}$ & $19 \mathrm{~K}$ & $27 \mathrm{Cu}$ & $35 \mathrm{Rb}$ & $43 \mathrm{Ag}$ & $51 \mathrm{Cs}$ & $59 \mathrm{Ir} \& O s \& \mathrm{Pt} \& \mathrm{Au}$ \\
\hline $4 \mathrm{Be}$ & $12 \mathrm{Mg}$ & $20 \mathrm{Ca}$ & $28 \mathrm{Zn}$ & $36 \mathrm{Sr}$ & $44 \mathrm{Cd}$ & $52 \mathrm{Ba}$ & $60 \mathrm{Hg}$ \\
\hline $5 \mathrm{~B}$ & $13 \mathrm{Al}$ & $21 \mathrm{Sc}$ & $29 \mathrm{Ga}$ & $37 \mathrm{Y}$ & $45 \mathrm{In}$ & $53 \mathrm{La}$ & $61 \mathrm{Tl}$ \\
\hline $6 \mathrm{C}$ & $14 \mathrm{Si}$ & $22 \mathrm{Ti}$ & $30 \mathrm{Ge}$ & $38 \mathrm{Zr}$ & $46 \mathrm{Sn}$ & $54 \mathrm{Ce} \& \mathrm{Pr}$ & $62 \mathrm{~Pb}$ \\
\hline $7 \mathrm{~N}$ & $15 \mathrm{P}$ & $23 \mathrm{~V}$ & $31 \mathrm{As}$ & $39 \mathrm{Nb}$ & $47 \mathrm{Sb}$ & $55 \mathrm{Nd} \& S m \& G d \& E u \& \mathrm{Pm}$ & $63 \mathrm{Bi}$ \\
\hline $8 \mathrm{O}$ & $16 \mathrm{~S}$ & $24 \mathrm{Cr}$ & $32 \mathrm{Se}$ & $40 \mathrm{Mo} \& \mathrm{Tc}$ & $48 \mathrm{Te}$ & $56 \mathrm{Dy} \& E r \& H o \& T m$ & $64 \mathrm{Po}$ \\
\hline
\end{tabular}

Figure 7. A speculative extension of Newlands' 1866 table with some later discovered elements up to element 84 . Some actual succession of the discovery, classification and correction of atomic weights with respect to Newlands' has been considered in the construction of this table. Of course, some overcrowded cells can be drawn into columns and still get some of the elements into correct rows.

Superficially, Newlands' ordinal numbers look suspiciously like atomic numbers in the contemporary periodic table: starting with ' 1 ' and proceeding with natural numbers. Wendell Taylor (1949) firmly holds that they are indeed atomic numbers, and, thus, that Newlands was a pioneer of those. Also Eric Scerri (2007, p. 76) claims (with a concession, though) that Newlands had "in a sense anticipat[ed] the modern notion of the atomic number" (also Scerri, 2005, p. 208; 1997, p. 241). However, I strongly oppose to this view on both metaphysical and technological grounds. Clearly, scientific technology was not yet as advanced as to detect any atomic, much less subatomic structures - the discovery of protons was still decades ahead. Additionally, as Newlands was reluctant to even use the terminology of atoms due to the prevailing ontological distrust in that notion, he could even less suspect that they had any structure, including a nucleus or its constituents. In measurement-theoretic terms, he could not have this kind of ERS behind the numbers of his NRS. Considering the discussion in the previous sections, both the possibility that the numbers assigned to elements changed, as well as more than one element was assigned the same number, speak against the atomic number interpretation of Newlands' ordering. Carmen Giunta presents, in principle, the same counterarguments to this interpretation, plus that as new elements were inserted, the ordinal numbers for the existing elements change (Giunta, 1999, p. 27), which means that the simple multiples of seven between analogous elements would no longer hold.

I conclude that Newlands' 1866 table implies no clear scale, that is, no NRS with an identifiable ERS and empirically applicable arithmetics. In his next table, 
post-Mendeleev in 1878 (Newlands, 1878, pp. 255-257; Fig. 8), he makes considerable changes that render it more systematic and enhance its potential predictive power. Firstly, his hypothesis is still that natural numbers provide the scale for elements according to atomic weight. To this aim, he interpolates the series of atomic weights with his ordinals by multiplication with a coefficient, taking something other than $\mathrm{H}$ as a unit $(\mathrm{Cl} \approx 15$ seems a good option). The predictions of new elements are based on the resulting series, where ordinals not approximated by any known element - gaps in the table —indicate yet unknown elements whose atomic weights would be $\mathrm{n} \pm \varepsilon$, with $\varepsilon<2$. Thereby he also reduces calculations of equivalents to calculations with ordinals, instead of with fractional equivalents. If nuclei only consisted of protons, this scale would be identical, or nearly so, with the contemporary table. Secondly, he has abandoned a rigid period for the entire realm of chemical elements and combines periods 7 and 10 in one table. This is his first step towards a variable period of the table.

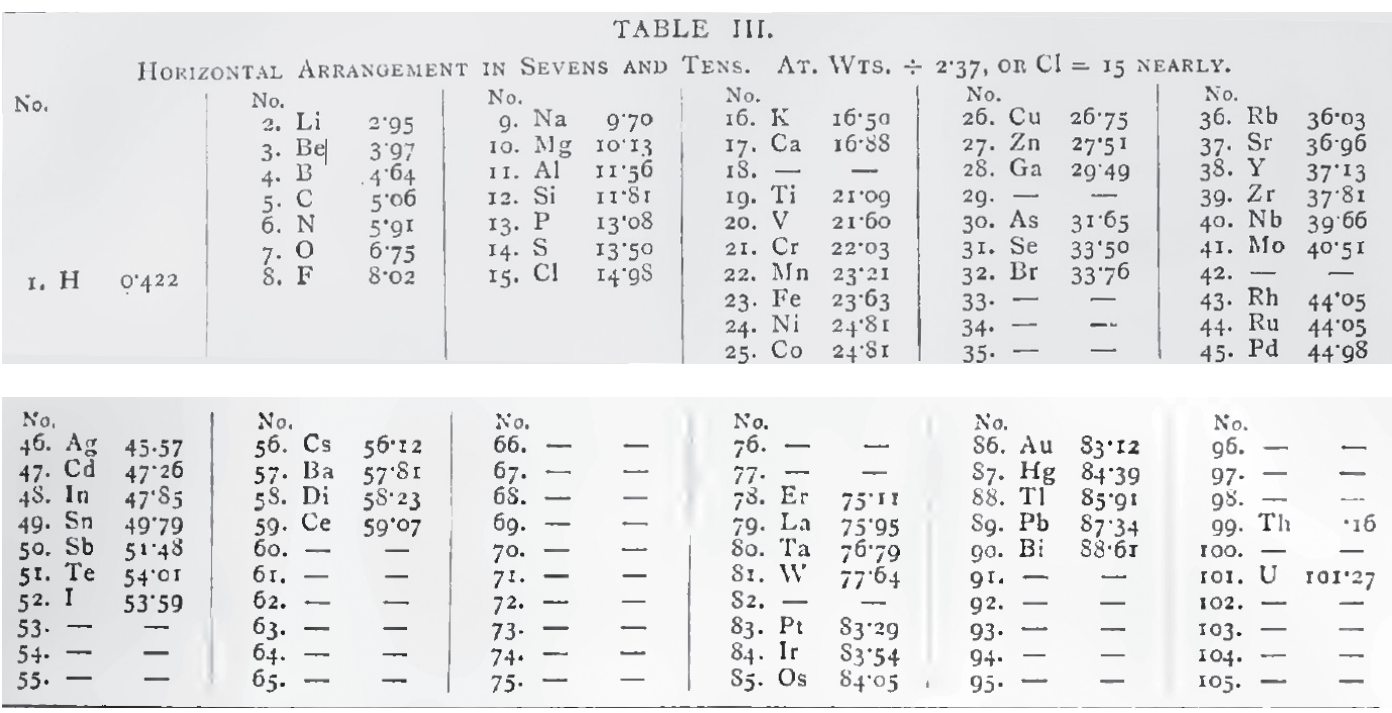

Figure 8. Newlands' table (Newlands, 1878, pp. 456-457). Atomic weights have been interpolated with ordinals by a linear transformation, providing a form of hypothesis for yet undiscovered elements.

Where Newlands does deviate even from this system is in his speculation about the possible existence of elements with equivalents as much above $\mathrm{U}$ and below $\mathrm{H}$ as is the distance between $\mathrm{H}$ and $\mathrm{U}-$ "there is no fixed limit to either maximum or minimum atomic weight" (even if gravimetrically difficult 
to measure) (Newlands, 1878, p. 256). Assuming that atomic weight is still a positive quantity, this would lead to real numbers, as "no fixed limit to a minimum" means infinitely close to zero-not even fractions like with the Prout-plus-Marignac type of hypothesis explored above. This would even rule out atom. But if real numbers between 0 and 1 are allowed, why not also allow numbers above 1? So we would end up with a scale of real numbers with no natural unit. If all of its points had a counterpart in an ERS, there should be an infinite number of different elements.

\section{Mendeleev's table}

Dmitri Ivanovich Mendeleev (1834-1907) is sometimes incorrectly credited as the first to formulate the periodic table in its contemporary shape (see Lothar Meyer, 1864, for an earlier version). Figure 9 (see p. 24) shows the version published in Russian in 1871 (Mendeleev, 1871, p. 31; the German version was published in 1872), which is more complete than the first version of 1869 . Compared to the first version, the additions are indication of groups, the explicit inclusion of gaps for yet unknown elements and of the secondary basis of ordering - chemical reactivity, or typical formulae with the standard elements $\mathrm{O}$ and $\mathrm{H}$.

Mets (2019, p. 83) emphasises that, for Mendeleev, chemical elements were individual entities (Mendeleev, 1905, pp. 11, 27), and atomic weight was the most fundamental, defining and individuating property of an element, as the only known property of an element (not of simple body) that does not change (or is common) over the changes in its circumstances such as the compounds it enters (Mendeleev, 1869, p. 66). ${ }^{9}$ However, Mets (2019) does not notice the full import of this for her analysis of measurement theory. Besides being the primary ordering principle (Mendeleev, 1871, p. 32), this also means that hydrogen is the weight unit merely metrologically or for the NRS, assigned numbers being non-integral multiples of the atomic weight of $\mathrm{H}$, not ontically or for the ERS. Mendeleev strictly opposed the ontological Prout's hypothesis, for the latter meant that chemical elements are in principle reducible to a primary matter and

9 However, Mendeleev is not quite consistent in this issue. For instance, in his 1871 table (Fig. 9) he has $\mathrm{Rb}$ with two considerably different atomic weights (85 and 104) and thus occupying two places in the table. Also many sets of elements have the same atomic weight, such as $\mathrm{Ni}$ and $\mathrm{Co}$ (although in 1870, p. 70, Mendeleev has the atomic weight of nickel $\mathrm{Ni}=59.5$ ), and $\mathrm{Ru}, \mathrm{Rb}$ and $\mathrm{Pd}$ all 104, $\mathrm{Pt}=\mathrm{Au}=197$. 
thus not individual. Mendeleev's belief in the individuality of elements means both that each has its unique and unchanging atomic weight, and that their atoms cannot be structurally analysed (Gordin, 2004, pp. 215-216). ${ }^{10}$

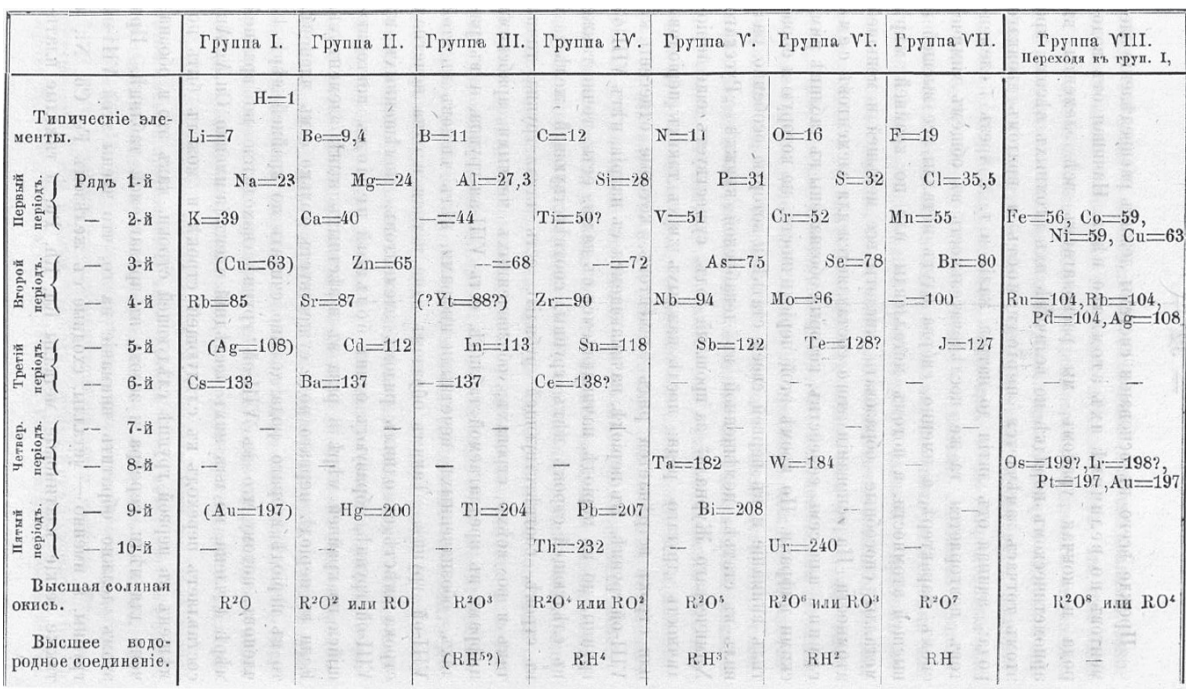

Figure 9. Mendeleev's 1871 table (Mendeleev, 1871, p. 31). Upper row: “Group I, ... Group VII, Group VIII (Continue with group I)”; left column: “Typical elements [Li, ..., F]; First period \{Row 1st [Na, ..., Cl]; [Row $]$ 2nd [K, ..., Co]\}; ...; Fifth period $\{[$ Row $]$ 9th $[(\mathrm{Au}), \ldots, \mathrm{Bi},-,-$ - $;$; Row $]$ 10th [-, ..., Ur, - ]; Higher salt-forming oxide ${ }^{11}$; Higher hydrogen compound.

What are the implications of this to the scale of the phenomenon? The individuation function of atomic weight resembles the contemporary table in which the atomic number is the individuating property. Thus it is like the name of an element-which would imply a nominal scale. But unlike in nominal scale, here again — and even more so than with atomic numbers-a meaningful and even practically useful arithmetic is defined in that scale. Addition and subtraction of atomic weights, as mentioned above, were and are the necessary mathematical basis for accounting for chemical reactions.

10 Thus, Hettema's and Kuipers' (1988, p. 396) claim that Mendeleev "introduced in fact implicitly the atomic numbers" cannot hold since 'atomic number' refers to a structural component of an atom. Also Scerri $(2005$, p. 208; 1997 , p. 235) criticises this interpretation.

11 This means that they "contain most oxygen and are able to form salts" (Mendeleev, 1905, p. 20). In Mendeleev (1870, pp. 14-15), he explains that although most elements form varying oxides, most of those are of very low stability and cannot form salts; thus he considers only those that can form salts, and thereby the highest oxidation of elements "setting the limit for salt-forming oxide". 
The assigned NRS also allowed meaningful extrapolation of the scale. Although the tabular shape arranges elements into a regular grid with equal distances between them, the real atomic weights have imprecise differences; thus, the extrapolation of corresponding atomic weights by Mendeleev was also approximate. Without tolerating inexactitude and approximation, the intrapolation of the atomic weights into a regular grid, maintaining the measured atomic weights, would not have been possible in the first place. ${ }^{12}$ Furthermore, certain restrictions to the tolerated inexactitude, and the groups as defined through their compounds with standard elements $\mathrm{H}$ and $\mathrm{O}$, are an indispensable theoretical basis for the interpolation, as evidenced by the set of gaps left from Group V, Row 6, until Group IV, Row 8, where there are now rare earth metals lanthanides and actinides-firstly, the difference between neighbouring elements cannot be too big, and secondly, the neighbourhood is defined by groups.

However, due to the inexactitude, even if limited to some extent, Mendeleev could not set definite criteria for extrapolating the scales. And here we do not have to speculate, for he followed his ideas through into a more complete system in 1905, incorporating elements discovered in the meantime (Figure 10 on p. 27 shows the upper fraction of that table). While for elements from $\mathrm{Li}$ to $\mathrm{U}(\mathrm{Ur})$, the differences between atomic weights are more or less between 0.9 and 3, then placing six hypothetical elements between $\mathrm{H}=1,008$ and $\mathrm{He}=4$, the differences between their atomic weights should be 0.5 on average, ${ }^{13}$ and those of the seven hypothesised elements between the hypothesised elements aether or newtonium $x$ $(\approx 0.0000001$ weight of $\mathrm{H}$; Mendeleev, 1905 , p. 36) and coronium $y$, about 0.14 in average. While the differences between the equivalents of analogous elements were found as arithmetic extensions for triads $\left(\mathrm{E}_{\mathrm{k}}=\mathrm{a} \times\left(\mathrm{b} \times \mathrm{E}_{1}+\mathrm{c} \times \mathrm{E}_{\mathrm{m}}\right)\right)$, Mendeleev here uses in a sense a similar schema for approximate numeric determination of the equivalents of $x$ and $y$, only as the geometric extension $\left(\mathrm{E}_{\mathrm{k}} / \mathrm{E}_{1}>\mathrm{E}_{\mathrm{m}} / \mathrm{E}_{\mathrm{n}}-\mathrm{He}: y\right.$ $>\mathrm{Li}: \mathrm{H} ; \mathrm{Ne}: \mathrm{He}>\mathrm{Na}: \mathrm{Li}>\mathrm{Mg}: \mathrm{Be} .$. ) without justifying it by expanding to the entire table. The justification stems from the corresponding ERS instead, based on chemical, physical and astronomical considerations (permeability of matter, chemical inertia, the ability to escape the gravitational field of the most massive celestial bodies). As Mendeleev regards elements to be individual, there is no reason to need $x$ to engender another fine-grained scale, as would be necessary if it were

12 Béguyer de Chancourtois, as noted above, indeed rounded the measured equivalents into integers to get a regular grid; even the equivalent of $\mathrm{Cl}$ is rounded to 35 in his helix.

13 As Petruševski and Cvetković (2018) show, the placing of hydrogen in the periodic table is ambiguous: it could be in the group of $\mathrm{Li}$, of $\mathrm{F}$, of $\mathrm{C}$, above $\mathrm{Li}$ and $\mathrm{F}$, or separately of all groups. Had Mendeleev known to doubt those locations, his resulting system, and its implications to the NRS, would have accordingly differed. 
the protyle. One can even speculate if in those intervals, the interval scale instead would be applicable, as the two points are numerically fixed- $\mathrm{H}$ and $\mathrm{He}$ in one interval, and $\mathrm{H}$ and $x$ in the other interval. But similarly to his other predictions, the four neighbouring elements (left and right, above and below) are fixed and determine the interval, and how many more elements should be found in that interval, so the equivalents of the hypothetical elements are determined by the interval method. At the same time, though, the defined units are not as arbitrary as in the case of true interval scales like temperature; the fixed measured points are not at all arbitrary, and are mostly approximate.

Further irregularities in his table concern periodicities. The 1871 table contains three kinds: $\mathrm{H}$ separately — a period of one, thereafter a period of seven typical elements, and then periods of eighteen (in (1871, p. 33), Mendeleev writes ' 17 '), divided into rows of seven and eleven. Division into rows is justified with chemical and physical properties: in even-numbered rows, for instance, elements have more energetic bases, and no metal-organic nor hydrogen compounds are known for them. Periodicity has changed in the 1905 table: the first four periods consist of eight elements each (part of these hypothetical)_added are noble gases, discovered since the 1890s, intermittently following periods of twelve and seven elements. No reason is given for not hypothesising noble gases to uneven rows, even though the 3 rd row does have one; and he dares to speculate that only the 7th group (halogens) still has a member in the 1st row (Mendeleev, 1905, p. 23).

Concerning the secondary principle of ordering for Mendeleev, Mets (2019, p. 78) claims it to be valency, or "how many univalent atoms [an element] is able to combine with". However, this is not entirely correct, as the concept of valency was still unclear at that time. Mendeleev does seem to define valency on reactivity with $\mathrm{Cl}$ as giving mostly one type of compounds, even though there are exceptions (Mendeleev, 1871, pp. 37-42). In his 1869 work, Mendeleev (1869, pp. 61-64) discusses basing the system on valency, stating that elements have different valencies in the different compounds they enter. In 1870, Mendeleev (1870, p. 20) concluded his discussion on this topic by disconnecting the notion of valency from that of compounds: "the amount of elements that combine to form a particle is governed by a few, not yet formulated but obviously simple and general laws which have nothing in common with the concept of valency of elements." What he takes as characteristics corresponding to the groups of allied elements, underlying the secondary ordering, is their saturated oxides that can form salts (see Fig. 9 on p. 24; Mendeleev, 1870, pp. 15-16; not included 


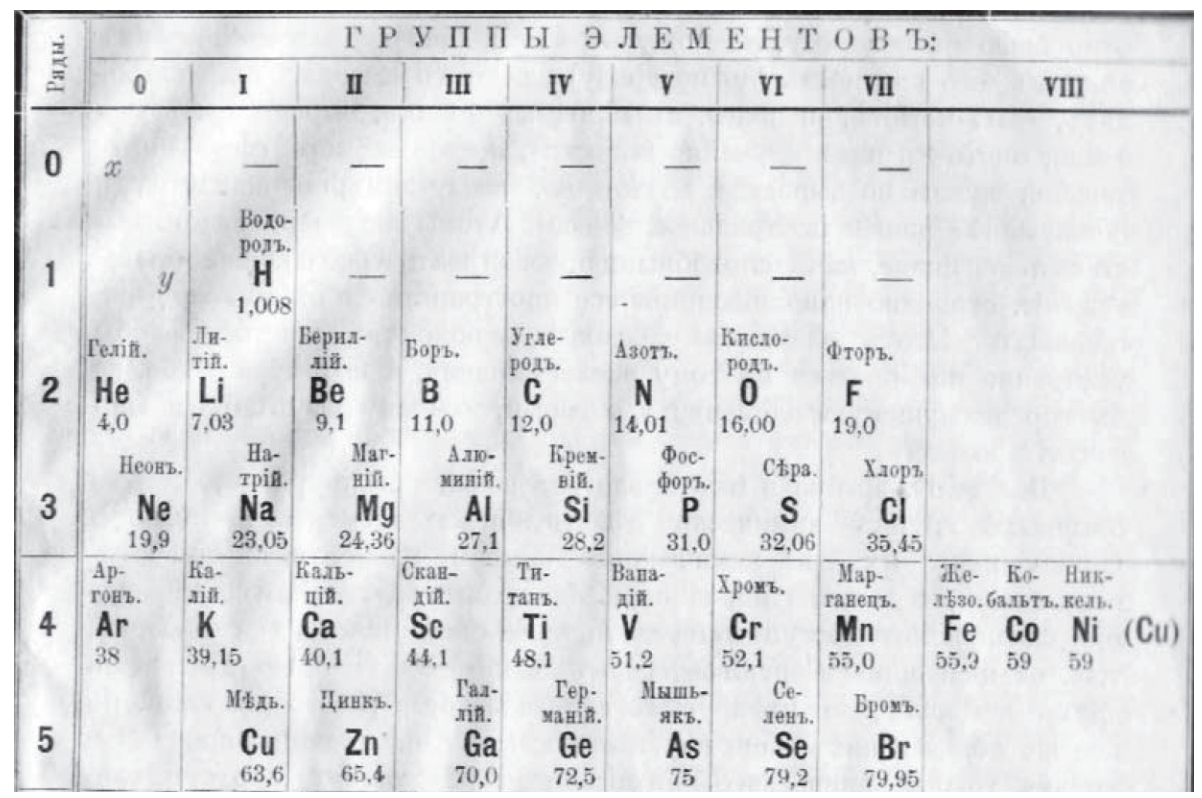

Figure 10. The upper fraction of Mendeleev's 1905 table with further predictions of newtonium or aether $(x)$ and coronium $(y)$, and the elements hypothesised between those and between $\mathrm{H}$ and $\mathrm{He}$, indicated (Mendeleev, 1905, p. 25).

in the 1905 table). He includes in the table typical or the most stable hydrogen compounds, noting that in those, and oxygen and chlorine compounds, elements have different valencies.

The practical import of concatenation of equivalents was mentioned above. For Mendeleev, it even has hypothetical theoretical import with respect to the secondary ordering principle, potentially making equivalents both the primary and the secondary ordering principles. This is exactly what Mets (2019, p. 78) mentions about the primary ordering principle, atomic numbers, that their concatenation gives a new, although substantially unimportant equivalence class in the NRS, but not in the ERS: " $\mathrm{Z}(\mathrm{Cl})=17,[\ldots] \mathrm{Z}(\mathrm{O}+\mathrm{H})=17$, but $\mathrm{Cl} \neq \mathrm{OH}$ ". Precisely this type of concatenation, but applied to atomic weights, would make substantial sense in Mendeleev's primary ordering principle—it would yield the secondary ordering principle in terms of NRS:

Sodium is monovalent; therefore it forms compounds $\mathrm{Na}_{2} \mathrm{O}$ and $\mathrm{NaHO}$. Its equivalent equals 23. Magnesium is bivalent and forms an oxide of the form $\mathrm{MgO}$; its equivalent equals 24 . Thereby with one equivalent of oxygen in magnesium oxide, 24 parts of this element are added, exactly like in 
caustic soda there are 23 parts of sodium and 1 weight part of hydrogen. Magnesium is equivalent to hydrogen sodium and even equal with it in weight. (Mendeleev, 1870, p. 21)

The same is said to hold for $\mathrm{Ca}$ and $\mathrm{K}$, as if "calcium was the synthesis of hydrogen with potassium", and so forth until a certain limit, from where it starts from the beginning. And so "with respect to the ability to form known atomic compounds, exists periodicity of dependence on atomic weight" (Mendeleev, 1870, p. 21). Obviously, this can only pertain to NRS, not ERS, since for Mendeleev elements were simple individuals, not consisting of other matter. However, the arithmetics of valency that it suggests must again be allowed considerable deviation tolerance, since the differences between the equivalents of successive elements are often other than the equivalent of hydrogen.

\section{Conclusion}

Mets (2019) presumes without detailed justification that Suppes' and Zinnes' measurement theory applies to the ordering of chemical elements. Here the several stages of the evolution of chemistry and of the periodic table have been analysed to test this presumption. The matter turns out to be more complicated than Mets assumed. Mainly, it is difficult to accord the scale types to any of those different versions of the table, taking into account the conceptualisations or ontological accounts of chemical elements and their relations to each other. Most have features of different scale types, and so they do not fully correspond to any of them. The identifying function of assigned numbers, either on the basis of atomic weight or atomic number, works like a nominal scale but, unlike the latter, has substantial meanings; only in Newlands' earlier table nominality may be real, but even he foresaw an arithmetic function to the assigned numbers, first of all stating the ordering of elements according to equivalent. Thus his scale is partly an ordinal scale (also in the later table), but he does attempt to define addition (concatenation, in ERS) on it. Ratio scale applies to most conceptualisations, either on the basis of $\mathrm{H}$ or some of its fraction, or some other element, as the metrological unit, and in H-based systems possibly also the ontological unit; but unlike the usual ratio scales, not all ratios are deemed empirically referentialthe scale of elements is discrete, not continuous. In systems based on structured atoms consisting of like particles, such as the number of protyle or protons, the absolute scale comes to mind, but this only holds for the element identification 
phase, for neither those NRSs nor ERSs really function according to that scale. Some features of the interval scale have a role in prediction, but the fixed points and intervals are not arbitrarily chosen.

All that does not refute Mets' conclusions but it shows that the applicability of the simplified and quite theoretical measurement theory of Suppes and Zinnes may not be adequate for the chosen case study. Both metaphysical and numerical assumptions are well there in the conceptualisations of chemical elements, pertaining to the ERS and the NRS accordingly. An operationalist and/or a model-based measurement theory might provide more insight into the metrology of the periodic system, but could not be included in this discussion.

What can be said about the dual nature of chemistry on the basis on these conclusions? Certainly, the contemporary ordering of elements follows a strict and precise scale—natural numbers assigned to equivalence classes (or elements). Compared to that, the equivalent-based scales were approximate, imprecise and statistical in character, the equivalence classes had unequal differences and sometimes were even reversed. The rigging that both Newlands and Mendeleev but also others had to undertake to create a system according to the common perception of the elements' similarities and differences were numerically irregular and ad hoc. Going further back, the quantification (weights of reactants) and quantisation (equivalent weights), which met some resistance (Berthollet; cf. also Mendeleev's reports on multiatomicity), were crucial steps for chemistry developing this exact core of what the periodic table now is. Starting with a halfratio scale (equivalents), to a half-ordinal scale (ordering elements), to a firmer but irregular half-ratio scale (atomic weights), to a precise and regular half-ratio scale (atomic numbers), is certainly an evolution towards further exactness.

\section{Acknowledgements}

Great thanks go to the referees for their helpful comments, and to Klaus Ruthenberg for the discussion that also informed this paper. The article is based on presentations at the conference 'From $\varphi$-science to practical realism: an international conference in honour of Rein Vihalemm (1938-2015)' (13-14 August 2019, Tartu) and the University of Oulu philosophy seminar (3 October 2019). I thank the participants of these events for the discussions that have helped to improve the presentation of the topic. 
The work has been supported by the University of Tartu grants PHVFI16941 and PHVFI20930, the Estonian Research Council grants nos. IUT20-5 and PRG462, and the European Regional Development Fund (Centre of Excellence in Estonian Studies).

\section{References}

Béguyer de Chancourtois, A.-É. (1862), 'Sur un classement des corps simples ou radicaux appelé vis tellurique' [On a classification of simple bodies or radicals called telluric helix], Comptes rendus. Hebdomadaires des séances de l'Académie des Sciences, Paris: Imprimerie de Mallet-Bachelier, pp. 757-761, 840-843, 967-971.

Berzelius, J. J. (1835), Théorie des proportions chimiques: et table synoptique des poids atomiques des corps simples, et de leurs combinaisons les plus importantes [Theory of chemical proportions: and a synoptic table of atomic weights of simple bodies, and their most important compounds], Deuxième Édition, Paris: Firmin Didot Frères.

Döbereiner, J. W. (1829), 'Versuch zu einer Gruppierung der elementaren Stoffe nach ihrer Analogie' [An attempt of grouping elementary substances according to their analogy], Annalen der Physik und Chemie, vol. 15, no. 2, pp. 301-307. https://doi.org/10.1002/andp.18290910217

Dumas, J.-B. (1859), Mémoire sur les équivalents des corps simples [Disquisition on the equivalents of simple bodies], Paris: Mallet-Bachelier.

Dunsch, L. (1986), Jöns Jacob Berzelius. Biographien hervorragender Naturwissenschaftler, Techniker und Mediziner [Jöns Jacob Berzelius. Biographies of distinguished natural, technical and medical scientists], Band 85, Leipzig: BSB B. G. Teubner Verlagsgesellschaft. https://doi.org/10.1007/978-3-322-94554-9

Giunta, C. J. (1999), 'J. A. R. Newlands' classification of the elements: Periodicity, but no system (1),' Bulletin for the History of Chemistry, no. 24, pp. 24-31.

Gordin, M. D. (2004), A Well-Ordered Thing: Dmitrii Mendeleev and the Shadow of the Periodic Table, New York: Basic Books.

Hand, D. J. (2004), Measurement Theory and Practice: The World through Quantification, New York: Oxford University Press.

Hettema, H. \& Kuipers, T. A. F. (1988), 'The periodic table-its formalization, status, and relation to atomic theory,' Erkenntnis, vol. 28, pp. 387-408.

Hettema, H. \& Kuipers, T. A. F. (2000), 'The formalisation of the periodic table,' Poznan Studies in the Philosophy of the Sciences and the Humanities, vol. 75, pp. 285-305. 
Lothar Meyer, J. (1864), Die modernen Theorien der Chemie und ihre Bedeutung für die chemische Statik [Modern theories of chemistry and their significance for chemical statics], Breslau: Verlag von Maruschke \& Berendt.

Mendeleev, D. I. (1869), 'Sootnoshenie svoistv s atomnym vesom elementov' [On the relationship of the properties of elements to their atomic weights], Zhurnal Russkago Khimicheskago Obshchestva, vol. I, pp. 60-76.

Mendeleev, D. I. (1870), 'O kolichestve kisloroda v solianykh okislakh i ob atomnosti elementov' [On the quantity of oxygen in salt-forming oxides and valency of elements], Zhurnal Russkago Khimicheskago Obshchestva, vol. II, pp. 14-21.

Mendeleev, D. I. (1871), 'Estestvennaia sistema elementov i primenenie eia k ukazaniiu svoistv neotkrytykh elementov' [The natural system of elements and its application to indicating properties of yet uncovered elements], Zhurnal Russkago Khimicheskago Obshchestva, vol. III, pp. 25-56.

Mendeleev, D. I. (1872), 'Die periodische Gesetzmässigkeit der chemischen Elemente' [The periodic lawfulness of the chemical elements], transl. by Felix Wreden, Annalen der Chemie und Pharmacie Supplement 8, pp. 133-229.

Mendeleev, D. I. (1905), Popytka khimicheskago ponimaniia mirovogo ethira [An attempt towards a chemical conception of the world aether], St. Petersburg: Tipo-litografija M. P. Frolovoi.

Mets, A. (2019), 'A philosophical critique of the distinction of representational and pragmatic measurements on the example of the periodic system of chemical elements,' Foundations of Science, vol. 24, no. 1, pp. 73-93. https://doi.org/10.1007/s10699-018-9567-x

N(ewlands), J. A. R. (1863), 'On relations among the equivalents,' Chemical News, vol. 7, pp. 70-72.

Newlands, J. A. R. (1864), 'Relations between equivalents,' Chemical News, vol. 10, pp. 59-60.

Newlands, J. A. R. (1865), 'On the law of octaves,' Chemical News, vol. 12, p. 83.

Newlands, J. A. R. (1878), 'On relations among the atomic weights of the elements,' Chemical News, vol. 37, pp. 255-256, 257.

Petruševski, V. M. \& Cvetković, J. (2018), 'On the 'true position' of hydrogen in the periodic table,' Foundations of Chemistry, vol. 20, no. 3, pp. 251-260. https://doi.org/10.1007/s10698-018-9306-y

Restrepo, G. (2018), 'The periodic system: a mathematical approach,' in E. Scerri \& G. Restrepo (eds.) Mendeleev to Oganesson. A Multidisciplinary Perspective on the Periodic Table, New York: Oxford University Press, pp. 80-103.

Scerri, E. R. (1997), 'Has the periodic table been successfully axiomatized?' Erkenntnis, vol. 47, pp. 229-243. https://doi.org/10.1023/A:1005318720779

Scerri, E. R. (2005), 'On the formalization of the periodic table,' in A. Festa, A. Aliseda \& J. Peijnenburg (eds.) Cognitive Structures in Scientific Inquiry (Poznań Studies in 
the Philosophy of the Sciences and the Humanities), Amsterdam \& New York, NY: Rodopi, vol. 84, pp. 191-210. https://doi.org/10.1163/9789401201339_009

Scerri, E. R. (2007), The Periodic Table: Its Story and Its Significance, Oxford: Oxford University Press.

Suppes, P. \& Zinnes, J. L. (1962), Basic Measurement Theory, Technical Report no. 45, March 15, 1962, Psychology Series, Stanford, CA: Stanford University.

Taylor, W. H. (1949), 'J. A. R. Newlands: A pioneer in atomic numbers,' Journal of Chemical Education, vol. 26, no. 9, pp. 491-496. https://doi.org/10.1163/9789401201339_009

Venable, F. P. (1896), The Development of the Periodic Law, Easton, PA: Chemical Publishing Co.

Vihalemm, R. (2019/1981), A Story of a Science: On the Evolution of Chemistry, Special Issue of Acta Baltica Historiae et Philosophiae Scientiarum, vol. 7, no. 2. https://doi.org/10.11590/abhps.2019.2.01

Williamson, A. W. (1866), 'Proceedings of societies. Chemical Society. Thursday, March 1,' Chemical News, vol. 13, p. 113.

Ave Mets is a senior research fellow of philosophy of science at the Institute of Philosophy and Semiotics, University of Tartu. 